The application of social innovation as it relates to older people and the implications for future policy-making: A scoping review

\begin{abstract}
Social innovation has received increasing attention in recent decades (Agostini et al. 2017). This article considers how the concept has been applied to the issue of ageing and what can be learnt about effective policy responses.
\end{abstract}

The acknowledged lack of understanding generally about the concept makes it timely to undertake a scoping review of the current evidence from social innovation projects associated with older people. A scoping review is considered appropriate where there is a need to 'identify and analyse knowledge gaps" (Munn et al 2018 p2).

Findings from the scoping review indicate that as yet the concept of social innovation is not fully defined. However, it has wide-spread appeal across a diverse range of disciplines has the potential to generate innovative policy responses.

A key argument identified is the need to change the public's perceptions of ageing and devise public policies that encourage and nurture age-friendly communities. In summation although social innovation has the potential to act as a policy driver, to be effective, it is necessary to devise robust strategies to ensure full user-engagement and active involvement of communities. Therefore, it is the process of delivery that needs urgent attention in any future research into social innovation.

Key words: Ageing, Social innovation, Process of delivery, User-engagement, policy making

\title{
Introduction
}

The growth of the ageing population world-wide is of particular concern given the implications this has for increasing the costs of health and social care provision. Hence there is a need to look at new and different strategies for working with the older population to address current and future challenges. One potential solution could be to 
introduce new support mechanisms that could maintain the independence of older people for longer. Social innovation is a concept that may generate valuable new ways of thinking about support options. The concept has received increasing attention from academics over the last few decades (Agostini et al. 2017). However the literature highlights that although there has been increasing research interest in the concept the 'state of knowledge continues to be fragmented' (van der Have and Rubalcaba, 2016, p.1923) with regard to how social innovation can be effectively employed. The acknowledged lack of understanding generally makes it timely to undertake a scoping review of the current evidence from social innovation projects associated with older people. Munn et al. (2018) highlight how scoping reviews are appropriate when a literature review seeks to consider specific issues such as:

"to clarify key concepts/definitions in the literature, to identify key characteristics or factors related to the concept and identify and analyse knowledge gaps"

(Munn et al 2018 p2).

A scoping review is therefore appropriate at this time.

\section{Literature search}

Recent research by the OECD has considered how innovation might be measured which resulted in four types of innovation being defined (OECD/Eurostat 2018). However, an initial review of the literature appeared to indicate that only limited research had been undertaken on what impact social innovation could have upon service delivery. Of particular interest was how social innovation might be applied to support older people and the literature search sough research evidence that might address this topic.

The literature highlighted that constructing a literature search may be problematical because:

"The diversity of conceptualizations creates ambiguity in the use of the term"

(van der Have and Rubalcaba 2016 p.1925). 
This indicated that rather than using a single term to define social innovation within the search strategy, several may be required. For example, the term social entrepreneurship appeared to be used interchangeably with social innovation. Further test searches indicated that including social entrepreneurship in the search strategy increased the yield but not the precision when combined with other search terms. An additional refinement to the search strategy was to search for the term social innovation within the title and abstract. Limiting the search to these areas provided a strong indication of the concept being a key focus of the article. A search strategy was built around three domains that combined the term social innovation with other terms that focused on health and wellbeing initiatives involving older people. These 3 domains were:

1. Terms to describe the concept of social innovation.

2. Terms that refined the search to focus on health and social care.

3. Terms that aimed to further focus the literature search by defining older people.

A piloted search indicated that including health and social care terms alongside terms for older people reduced the yield to only two articles, therefore the search structure was revised to focus on only two domains: social innovation and older people. This improved the yield but also retained the focus of the search. The finalised search strategy was then applied to the Academic Search Ultimate database that provided access to over 17,000 peer-reviewed journals and can simultaneously search multiple databases which include Medline Complete, CINAHL, EBSCO Host, PsycINFO and SocINDEX. Limiters were applied to the search and these restricted the search to peer reviewed articles published within the previous five years (2014-2019) and written in English.

As predicted, although there were high yields within the two search domains (social innovation and older people) the yield reduced significantly when combined leaving 48 articles. Alongside the search limiters the inclusion criteria for the review were:

- Articles that reported findings from a social innovation project involving older people, and;

- presented either a theoretical discussion or reported on a literature review of the topic. 
After removal of any duplications and applying the inclusion criteria the search yield was further reduced to a precision of 26 articles.

\section{Findings}

The literature search identified articles from a wide range of journals which reported on social innovation research from around the world. This diversity of application reflects a point frequently noted in the literature that there was wide-spread use of the concept across many disciplines ranging from rural development (Neumeier 2017) to technology (Kinder 2010).

However, despite the diversity captured by the search strategy it was noted that few of the large scale social innovation projects that the authors were aware of such as InnovAge, an EU funded project or work undertaken by RAND Europe for the World Health Organisation (WHO) were discussed in any detail. Although reference was made within the articles to EU funded research projects there was mainly limited information. Therefore it was decided to undertake a further online search for any additional literature of relevance and to test whether findings had been disseminated outside of the published, peer reviewed, international literature. This led to the retrieval of several project reports for example the TEPSIE Report (2014) and online publications by specific centres for social innovation such as Stanford Graduate School of Business. These were not included in the review as their content did not meet the inclusion criteria which required the focus of the article to be upon the application of social innovation to projects involving older people. However, this process established that there was a body of knowledge relating to social innovation not found within academic journals. In terms of content there were a number of topics discussed within the articles meeting the inclusion criteria for this scoping review and these are shown in Table 1 below.

Some articles presented theoretical debates around the use of social innovation and there were also articles that described projects developed in both urban and rural locations. Two of the papers reported upon situations which are more unique. One reported upon a project developed to support older people rebuild their lives following an earthquake 
and the other project helped support communities return to daily life after a period of conflict. The search also captured several literature reviews on social innovation.

Table 1: Topics considered within the articles included with the current scoping review

\begin{tabular}{|c|c|c|}
\hline Topic & $\begin{array}{l}\text { Number of } \\
\text { times the } \\
\text { topic appears }\end{array}$ & Authors \\
\hline Views on aging & 5 & $\begin{array}{ll}\text { - } & \text { Aoo, Abe, \& Kano (2019) } \\
\text { - } & \text { Spinelli, Weaver, Marks \& Victor (2019) } \\
\text { - } & \text { Riva-Mossman \& Verloo (2017) } \\
\text { - } & \text { Luoma, Henriksson \& Vaarama (2016) } \\
\text { - } & \text { Dragusin, Welsh, Grosu, Iosif, \& Zgura (2015) }\end{array}$ \\
\hline $\begin{array}{l}\text { Project } \\
\text { descriptions }\end{array}$ & 4 & $\begin{array}{ll}\text { - } & \text { Liamputtong \& Sanchez (2017) } \\
\text { - } & \text { Grant, Pollard, Allmark, Machaczek \& } \\
& \text { Ramcharan (2017) } \\
\text { - } & \text { Focic (2017) } \\
\text { - } & \text { Yotsui, Campbell \& Honma (2016) }\end{array}$ \\
\hline Social capital & 3 & $\begin{array}{l}\text { - } \quad \text { Yiengprugsawan, Welsh \& Kendig (2018) } \\
\text { - } \quad \text { Chipps \& Jarvis (2016) } \\
\text { - } \quad \text { Andersen \& Bilfeldt (2015) }\end{array}$ \\
\hline Silver economy & 2 & $\begin{array}{ll}\text { - } & \text { Klimczuk (2016) } \\
\text { - } & \text { Santoro, Vera-Munoz \& Belli (2017) }\end{array}$ \\
\hline Engaging users & 2 & $\begin{array}{ll}\text { - } & \text { Stypinska, Franke \& Myrczik ( 2019) } \\
\text { - } & \text { Sinigaglia \& Neary (2015) }\end{array}$ \\
\hline $\begin{array}{l}\text { Home-based } \\
\text { support }\end{array}$ & 2 & $\begin{array}{l}\text { - } \quad \text { Riva-Mossman, Kampel, Cohen, \& Verloo (2016) } \\
\text { - Angelini, Carrino, Khaled, Riva-Mossman \& } \\
\text { Mugellini (2016) }\end{array}$ \\
\hline Active aging & 2 & $\begin{array}{l}\text { - Joe, Perkins \& Subramanian (2019) } \\
\text { - } \quad \text { Rutschmann (2017) }\end{array}$ \\
\hline $\begin{array}{l}\text { Role of social } \\
\text { entrepreneurs }\end{array}$ & 1 & - Grohs, Schneiders \& Heinze ( 2017) \\
\hline $\begin{array}{l}\text { Sharing } \\
\text { knowledge to } \\
\text { better support } \\
\text { older people }\end{array}$ & 1 & - Bjerregaard, Aciene \& Christensen (2018) \\
\hline $\begin{array}{l}\text { Partnership } \\
\text { working } \\
\text { (between } \\
\text { community } \\
\text { groups and } \\
\text { charities) }\end{array}$ & 1 & - Adisa (2018) \\
\hline $\begin{array}{l}\text { Life-long } \\
\text { learning }\end{array}$ & 1 & - Merriam and Kee (2014) \\
\hline
\end{tabular}




\section{Literature reviews}

Philips et al. (2015) undertook a systematic literature review which focused on the period $1^{\text {st }}$ January 1987 to 30th December 2012. Philips et al. (2015) believed that there was 'a need to collate different insights into social innovation and social entrepreneurship' (p428). Their purpose was to define the relationship between social innovation and social entrepreneurship and move towards 'a more coherent field of study' (p429). The review also aimed to use any identified cross-cultural studies to draw out common issues to emerge from research findings. An area, the authors suggest is particularly neglected by research is the process of social innovation.

The literature review by Paunescu (2014) focused on a longer period from 1966 until April 2014. The review sought to identify current trends in research into social innovation, social capital and corporate social responsibility.

Both literature reviews report an increasing interest in social innovation signalled by a rise in published articles on the topic. However there are some slight differences in opinion. Philips et al. (2015) report that the first use of the term was 1998 however in the review by Paunescu (2014) the findings indicate that between 1966 and 199325 articles had social innovation in their title and a further 44 articles appeared between 1994 and 1999. Philps et al (2015) state that 2012 was the most prolific year in terms of published articles but this was the final year covered by their literature search. The literature review by Paunescu (2014) which extends into 2014 finds that the period 2004 to 2014 are the most important years for the development of the concept but also finds that 2012 was the year with the highest number of published articles.

Philips et al (2015) note that with their review the largest number of articles originated from the USA with the UK the next largest contributor. Overall, they state that the articles included in their review show a bias towards Europe but argue this might be a reflection of limiting their search to articles written in English. However they do identify an emerging interest from countries such as China and Japan. 
It is apparent that this scoping review proves timely as it up-dates the findings of two earlier literature reviews on the topic. Also the current scoping review found a diverse range of publications across various disciplines as did Philips et al (2015) who suggested that this range of sources indicated that the concept still remains to some degree 'immature'.

The previous literature reviews by Philips et al (2015) and Paunescu (2014) indicated that 2012 was a key year in terms of publications. The current review which focused upon $1^{\text {st }}$ January 2014 to $31^{\text {st }}$ June 2019 would suggest that there was during 2014 and 2015 a decline in publications but a rise in 2016 with a peak in 2017. Since then there has been another decline in articles related to social innovation.

\section{Social innovation and older people.}

The current scoping review may be helpful in identifying a recent trend within social innovation. The earlier work of Philips et al (2015) described how the larger contributor was the USA. However, at the point of writing there was an indication of an emerging interest from other countries. The current scoping review which considers the period immediately following on from the work of Philips et al (2015) found fewer studies originating from the USA. It is of interest too, that Merriam and Kee (2014) when discussing countries that face the greatest challenges in terms of an ageing population cite many of the countries that have offered contributions to this scoping review see Table 2 below.

A notable point concerning social innovation reported in the findings of Yotsui et al (2016) was that women may benefit from a social participation approach more than men. However, their data was unable to distinguish whether the approach favoured women more because it had more appeal to women or whether there were greater opportunities for women to engage with this approach. As the study was conducted in Japan there may also be a cultural element influencing these findings. 
Table 2: Countries with greatest growth in older people (cited Merriam and Kee 2014) compared to sources of articles included in current scoping review.

\begin{tabular}{|c|c|}
\hline $\begin{array}{l}\text { Greatest growth in older } \\
\text { people as at } 2011 \text { cited } \\
\text { Merriam and Kee (2014) }\end{array}$ & $\begin{array}{l}\text { Number of times the country of origin for article included in } \\
\text { this study and year of publication }\end{array}$ \\
\hline Japan & 2 published during $2018 \& 2019$ \\
\hline Italy & 0 \\
\hline Germany & 1 published during 2017 \\
\hline Finland & $\begin{array}{l}2 \text { published during } 2016 \text { and as part of a cross-cultural } \\
\text { study during } 2017\end{array}$ \\
\hline Sweden & 1 published during 2018 reporting a cross-cultural study \\
\hline Bulgaria & $\begin{array}{l}1 \text { published during } 2017 \text { reporting on a cross-cultural study } \\
\text { with Bosnia-Herzegowina, Bulgaria and Belrus }\end{array}$ \\
\hline Greece & 0 \\
\hline Portugal & 0 \\
\hline Belgium & 0 \\
\hline Croatia & 0 \\
\hline
\end{tabular}

A significant area of discussion within the literature concerned views on ageing. These articles highlighted how the current age structure of the global population presents challenges now and more so in the future unless the ageing process was redefined and that this change was reflected within future policy making. One approach that could be utilised to redefine the ageing process is social innovation and indeed several articles highlight the earlier work of an EU funded programme FUTURAGE (2009-2011) (Stypinska et al 2019). This programme aimed to develop guidance on how research into ageing should develop over the next 10-15 years. As a result of this project seven major themes were identified as key priorities for ageing research in the future (Walker 2011) and these were:

- Healthy Ageing for More Life in Years.

- Maintaining and Regaining Mental Capacity.

- Inclusion and Participation in the Community and the Labour Market. 
- Guaranteeing the Quality and Sustainability of Social Protection Systems. Ageing Well at Home and in Community Environments.

- Unequal Ageing and Age-related Inequalities.

- Biogerontology: From Mechanisms to Interventions.

This scoping review identified a number of projects which had adopted social innovation as an approach to support older people within communities. The two most striking initiatives in terms of impact focused upon situations where the status quo had been removed by war or natural disaster (Focic 2017 and Yotsui et al 2016). In these situations it could be argued that there were few barriers to the adoption of the social innovation and heightened willingness to engage with the initiative as it represented the only potential viable option given their country's limited infra-structure and financial resources. Although these two projects were driven by extreme circumstances other articles capture a shift in emphasis on the issue of ageing and indicated a move away from what does society do with older people to how can we change society's perception of ageing.

The current scoping review appears to capture this changing picture of interest in the use of social innovation and this is indicated by Table 3 which potentially reflects the changing proportion of older people within a nation's population. Merriam and Kee (2014) predict that by 2050 although Japan will still top the list Portugal will move up into second place and new countries will appear such as Bosnia and Herzegovina $\left(3^{\text {rd }}\right)$, Cuba ( $\left.4^{\text {th }}\right)$ Republic of Korea ( $\left.5^{\text {th }}\right)$, Spain ( $\left.7^{\text {th }}\right)$, Singapore $\left(8^{\text {th }}\right)$ and Switzerland $\left(10^{\text {th }}\right)$.

Table 3: Number of articles originating from countries predicted to have the greatest number of older people by 2050.

\begin{tabular}{|l|l|}
\hline Country & Number of articles and year of publication \\
\hline Bosnia \& Herzegowina & $\begin{array}{l}\text { 2 both published during 2017 one as part of a cross-cultural } \\
\text { study with Belarus and Bulgaria }\end{array}$ \\
\hline Spain & $\begin{array}{l}\text { 1 published during } 2017 \text { as part of a cross-cultural study } \\
\text { with Finland, Netherlands \& UK }\end{array}$ \\
\hline Switzerland & 3 published during 2015, 2016 \& 2017 \\
\hline
\end{tabular}




\section{Social innovation and research}

Philips et al (2015) report that many of the articles included within their review outline exploratory research with the majority of studies being qualitative. They also note a large proportion of concept papers. Philips et al (2015) highlight too, that a key focus of the literature is on the role of the entrepreneur to the detriment of other aspects. A view echoed by Paunescua (2014) who notes a lack of research attention with regard to understanding the process of social innovation. It is possible that Angelini et al (2016) provide a partial explanation as they discuss how some social innovation projects may include commercial partners who are reluctant to share emerging knowledge out of concerned that publishing such detail would provide their competitors with a market advantage. Of those articles which report upon projects or present findings from a study the topics which emerged are shown in Table 3 above.

\section{Changing the narrative on ageing}

Merriam and Kee (2014) address what they term the myths about older people. One myth they highlight is that in terms of numbers rather than as a percentage of the population, it is developing countries where the greater number of older people live. Another myth is that contrary to what is written in the literature all older people do not age in the same way and in fact women have a biological advantage over men in the ageing process. Also the authors challenge the notion that old people are frail, have nothing to contribute and are an economic burden. This review suggests that papers such as that written in 2014 by Merriam and Kee started to refocus the discussion moving it away from how to manage an ageing population to how to change our perception of ageing to a more positive one and this still remains a key topic of debate (Spinelli et al 2019).

Later publications discuss how to achieve active ageing within society. For example RivaMossman et al (2016) when discussing home-based care argue that this requires the reinvention of ageing through a process that facilitates the 'transforming [of the] current narrative' (p255). A theme discussed by Yotsui et al (2016) when writing about the ageing population of Japan and the importance of the 'mobilisation of participation by older people' (p1052). Following an earthquake which fractured many communities 
through physical destruction of geographical areas and the relocation of partial communities meant older people felt isolated. Their project aimed to create a mutual support mechanism for older people and it was delivered by older people to older people. Yotsui et al (2016) argue that historically older people have been stereotyped as problematical and that a paradigm shift is needed which instead recognises older people as 'valuable social assets' (p1055) however states:

"Research literature falls short of outlining how to maximise the capacity of older people" (Yotsui et al 2016 p1057).

A key point not made anywhere within the literature reviewed is the importance of identifying and formally acknowledging the contribution made by older people and the value that their contribution has to a social innovation project.

Rutschmann (2017) supports the arguments made above by Yotsui et al (2016) and calls for organisations to move away from 'doing things FOR older people to doing things WITH or BY older people' (p1). The findings of Focic (2017) indicate the benefits of such an approach as two-thirds of older people felt better for being involved in a social innovation project. In this particular study, Focic (2017) reports on a scheme established in Bosnia and Herzegovina where many social ties had been lost due to war and nearly $60 \%$ of older people had no access to old-age pension provision or similar. This social innovation project differed from others found within the literature reviewed as it was not a scheme that specifically targeted older people but one that was intended to influence the life of the whole community. The impact of this social innovation was to create a more age-friendly environment, support the development of a home-based care network and enhance the wellbeing of older people through raised self-esteem from being seen to make a valuable contribution to the life of the community. Focic (2017) concludes that the project's approach provides:

"integrated community-based social care for older people who are willing to donate their knowledge, expertise, experience and free time for the greater cause of preserving dignity and delivering a change that matters to people" (p8) 
Given the trend towards involving older people in the development of services and facilities that are age-friendly, an important issue to consider is user-engagement and this is a theme picked up within the literature reviewed.

Chipps and Jarvis (2016) highlight the importance of older people having influence on the direction their lives takes. This includes ensuring those engaging with older people make clear the role that older people have within the decision-making process. Riva-Mossman et al (2016) state that user involvement is of key importance to the success of any project but enabling this requires sufficient resources. Such resources include adequate funding and staff that share the philosophy of co-creation (Sinigaglia and Neary 2015). A further point the authors make is that older people should be engaged as stakeholders or coproducers of a new project from the outset and not at a later stage of project development. Santoro et al (2107) suggest that this is the only way to achieve a 'people-driven social innovation model' of delivery. Through early user involvement it is possible to establish whether the project is appealing, developed in a manner that is easy to use (accessible) and affordable (Sinigaglia and Neary (2015). The inclusion of service users in project development also has resonance with Spinelli et al (2019) who warn that services which are commissioned by others have a tendency for 'mission-drift'. Paunescu (2014) also believes that there is potential for projects to deviate from the intended mission due to issues such as competition amongst partners, limited resources and lack of support from formal bodies such as government.

\section{Discussion}

Although the literature highlights the importance of user involvement there is consensus concerning a lack of guidance on how to effectively achieve this and thus more research is required (Santoro et al. 2017, Riva-Mossman et al. 2016 and Sinigaglia and Neary 2015). Riva-Mossman et al. (2016) suggest that one user engagement strategy might be to connect with existing social networks within the community.

However, the discussion about targeting older people and engaging them with projects is somewhat at odds with another theme. The literature suggests that social innovation projects should not be specifically targeted at older people. Riva-Mossman et al (2016) 
argue that products or services should be designed not just for older people but for everyone. Evidence that this is achievable is found both in the research of Focic (2017) and in the general discussion that argues for a new narrative on ageing which the whole community can embrace. To do so requires a rethink about how we analyse situations and avoid focusing project planning and development solely upon specific groups. Therefore, it would appear if social innovation is to be an effective tool to redefine the ageing process then the whole community needs to be engaged in a conversation about the changing needs of its members across the life-span.

The idea of community-inspired social innovation projects responsive to the specific needs and preferences of a community suggests that the period between recognition of need and implementation of a solution could be shorter than a process that is managed by organisations (Adisa 2018). This is because informal partnerships within a community can be more responsive due to having greater flexibility than formal organisations that need to follow documented procedures and processes (Adisa 2018). However, informal partnerships may unintentionally exclude individuals. Partners already engaged could be perceived by others not yet engaged as holding a range of shared values which differ from their own and thus 'outsiders' are created who feel unable to participate (Grant et al. 2017). Also some forms of social innovation may need to be supported by the reframing of organisational policies as Schulmann et al. (2014) highlight:

"..these strategies have to be based on rights to social protection and other forms of social welfare, thus combining top-down and bottom-up initiatives that enable people to develop their own forms of activity." (Schulmann et al. 2014 p5)

Collectively this literature points to a need to look at how organisations can deliver in a more flexible way and/or how communities can develop inclusive partnerships which reflect the views of the whole community. The literature suggests such local partnerships are in a better position to move more quickly to implement a response. Indeed Spinelli et al (2019) argue that place-based social innovation projects are more likely to be effective and successful. However, Andersen and Bilfedt (2017) argue that localism can become a trap that inhibits the up-scaling of social innovation projects. 
There are indications throughout the literature reviewed that social innovation may be more effective in particular situations such as in urban areas or in particular circumstances such as where women are the intended recipients. However, the literature highlights that there has only been limited work into the application of social innovation. Philips et al (2015) argue that there is an urgent need to understand the management of social innovation. Of particular interest is the role that individuals/partners play in ensuring success and what type of networks effectively facilitate social innovation. Likewise Stypinska et al. (2019) argue that identifying how to create a successful model of social innovation would be beneficial as it would reduce set up costs by avoiding basic errors. Also any project that drew on best practice at the set up stage would yield a greater return on the original investment. However, Paunescu (2014) argues that:

"a stable and accurate measure of social innovation is neither possible or accepted" (p115).

Stypinska et al. (2019) agree and state that:

"The assessment of social impact of social innovations is a challenging task as there is no coherent approach to the measurement of social effect" (p4).

The literature notes that policy-makers have tended to focus upon specific issues facing older people such as healthcare (Angelini et al. 2016) or housing (Luoma et al 2016). Arguably when only one aspect such as housing is considered there is the potential that more creative or alternative options may be being overlooked. This suggests the need to move away from managing older people to creating instead more age-friendly communities.

\section{Conclusion}

This scoping review into the application of social innovation identified various issues. Most notably is that there is a body of knowledge related to social innovation which is missing from academic journals and therefore identify other sources such as project reports may extend current knowledge further. The more limited coverage with 
academic journals however, limits the debate around best practice in social innovation. Also this missing element within the academic literature may provide a false impression of how widespread the use of social innovation is as a solution or response to an issue. It is unclear why the findings from larger scale studies have not been published in academic journals but there is the suggestion made that this could be related to the commercial interests of some partners involved.

It is of note, based upon the currently available evidence that as yet social innovation has not been fully defined as a concept and furthermore that the process of social innovation is a specific area where research is lacking. Arguably, too, there seems some debate about how social innovation should be applied. Is social innovation a tool that can be utilised to address a single defined issue such as service improvements for the elderly? Or is a tactic that needs to be deployed to enable a shift in perceptions of a topic by communities or indeed wider society? The debate around how social innovation should be applied potentially hinders policy development. A possible way forward is for scrutiny of the delivery process of social innovation and its success or otherwise. Evidence and results drawn from projects utilising social innovation could be examined in terms of characteristics and process to search for commonalities that enhance the chances of success.

The current evidence offers strong arguments for not solely relying upon policies that offer guidance on active ageing. Instead a key argument which emerges from the literature would seem to be that more holistic responses are required and ones that create age-friendly communities. Thus, implying that future social innovation should focus on how this shift in whole-community thinking can be best achieved. Therefore, how to achieve effective user-engagement and active involvement in creating social innovation is an aspect of the process of delivery that needs urgent attention in any future research. 


\section{References}

Adisa 0 (2018) Third sector partnerships for older people insights from live at home schemes. Working with older people, 22, 3, 148-153

Agostini MR, Vierira LM, Tondolo RP and Tondolo VAG (2017) An overview of social innovation research: Guiding future studies. Brazilian Business Review. Available from: http://dx.doi.org/10.15728/bbr.2017.14.4.2. [Accessed 18 th January 2018].

Andersen J and Bilfedt A (2017) Transforming welfare institutions through social innovation and action research. International Journal of Action Research 03-201-220.

Angelini L, Carrino S, Khaled OA, Riva-Mossman S and Mugellini E (2016) Senior Living Lab: An ecologicalapproach to foster social innovation in an aging society. Future Internet 8,50 .

Chipps J and Jarvis MA (2016) Social capital and mental wellbeing in older people in a residential care facility in Durban, South Africa. Aging and Mental Health 20,12, 12641270.

Focic A (2017) Overcoming social exclusion and promoting dignity of older people in a post-war country. $17^{\text {th }}$ International Conference on Integrated Care 17, 5, A491:1-8.

Grant G, Pollard N, Allmark P, Machaczek K and Ramcharari P (2017) The social relations of a health walk group: An ethnographic study. Qualitative Health Research 27, $11,1701-1712$.

Kinder T (2010) Social innovation in services: Technology -assisted new care models for people with dementia and their usability. International Journal of Technology Management. 51, 1, 106-120.

Luoma M, Henniksson M and Vaarama M (2016). A note on social innovations for accessible housing for older people in Finland. Gerontechnology 15, 4, 243-244. 
Merriam SB and Kee Y (2014) Life-long learning: Important factors in healthy aging . Adult education Quarterly. 6, 2, 128-144.

Munn Z, Peters MDJ, Stern C, Tufanaru C, McArthur A and Aromataris E (2018) Systematic review or scoping review? Guidance for authors when choosing between systematic or scoping review. BMC Medical Research Methodology, 18 Article number 143.

Neumeier S (2017) Social innovation in rural development: identifying the key factors of success. The Geographical Journal. 183, 1, 34-46.

OECD/Eurostat (2018) Oslo Manual 2018: Guidelines for collecting, reporting and using data on innovation $4^{\text {th }}$ Edition The measurement of scientific technological and innovation activities. OECD Publishing, Paris/Eurostat, Luxembourg. https//doi.org/10.1787/978926430460-en.

Paunescu C (2014) Current trends in social innovation research: social capital, Corporate social responsibility, impact measurement. Management and marketing challenges for the knowledge of society 9, 2, 105-118.

Philips W, Lee H, James P and Gohabadian A (2015). Social innovation and social entrepreneurship: A systematic review. Group and Organisation Management 40 (3): 428-461.

Riva-Mossman S, Kampel T, Cohen C. and Verloo H (2016) The Senior Living Lab: An example of nursing leadership. Clinical intervention in aging. 11, 255-263.

Rutschumann C. (2017). Active, Empowered and young at heart. 17th International Conference in Integrated Care 17,5, A347: 1-8. 
Santoro R, Vera-Munoz C. and Belli A. (2017) People Olympics for social innovation: Cocreating the silver sharing economy for the aging society. International conference on Engineering, Technology and Innovation. 978-1-5386-0074-9/17.

Schulmann K. and Leichsenring K. with contributions by Casanova G. Ciucă V, Corcheş L, Genta M, Grigaliūnienė Z, Kucsera C, Matei A, Määttänen N, Naegele GPaat-Ahi G, Pîrciog S,Principi A,\& Rodrigues L ,Rodrigues R, Sănduleasa B, Schulze S, Reichert M, Szeman Z and Wall K. (2014) Social care and support and long term care in EU care regimes: Framework conditions and initiatives of social innovation in an active-aging prespective. Available at: https://www.euro.centre.org/downloads/detail/1523

Sinigaglia A and Neary D (2015) Putting users at the heart of care: engaging the' caredfor' in integrated innovation. International Journal of Integrated Care, Annual Conference suppl.

Spinelli G, Weaver P, Marks M and Victor C (2019) Making the case for creating Living Labs for aging in place: enabling socially innovative models for experimentation and complementary economies. Frontiers of sociology, 4, Article19, 1-16.

Stypinska J, Frankie A, and Myrczik J, (2019) Senior Entrepreneurship: The unrevealed driver for social innovation. Frontiers of Sociology 4, 30.

TEPSIE (2014) Social Innovation Theory and Research: A Summary of the Findings from TEPSIE.' A deliverable of the project: "The theoretical, empirical and policy foundations for building social innovation in Europe. (TEPSIE), European Commission - 7th Framework Programme, Brussels: European Commission, DG Research.

Van der Have RP and Rubalcaba L(2016). Social innovation research: An emerging area of innovation studies? Research Policy 45: 1923-1935.

Walker A (2011) FUTURAGE: A Road Map for European Ageing Research Available at https://www.age-platform.eu/sites/default/files/Research-briefing futurage.pdf [Accessed July 2019] 
Yotsui M, Campbell C and Honma T (2016) Collective action by older people in natural disasters: the Great East Japan earthquake. Aging and Society 36, 1052-1082. 